different universities before framing regulations concerning their mutual arrangements.

I am, Sirs, yours faithfully,

$$
\text { D. R. 'YATA, L.M.\& S. Bombay. }
$$

** If our correspondent will refer to p. 1448 of 'I'HE LANCET of Nov. 19th, 1904, he will there see a letter from Mr. S. B. Gadgil giving similar information and a note by ourselves stating that according to the testamur the L.M. \& S. of the University of Bombay is called a degree.-ED. L.

\section{THE TREATMENT OF STRABISMUS.}

\section{To the Editors of THE LANCET.}

SIRS, - With respect to the operation of lengthening the tendon in cases of strabismus, described in THE LANCET of Jan. 28th (p. 254), by Dr. Landolt of Paris, I may perhaps be permitted to point out that I adopted a similar operation several years ago. In July, 1902, I read a note upon my method before the Ophthalmological Society and at the same time showed several patients upon whom the operation had been performed. I showed by diagrams that the tendon of the internal rectus might be lengthened in several ways without disturbing its insertion into the sclera. My communication was published in the Society's Transactions, vol. xxii. (1902), p. 276. I believe I am correct in claiming that I was the first to devise and to perform the operation now described by Dr. Landolt under the name of "muscular elongation." I am, Sirs, yours faithfully,

Welbeck-street, W., Jan. 30th, $1905 . \quad$ SYDNEY STEPHENSON.

\section{THE QUESTION OF TESTIMONIALS.}

\section{To the Editors of THE LANCET.}

SIRs, - My attention has been called to an advertisement in THE LANCET with the facsimile of a letter, or part of a letter, commending a medical preparation, which is signed "Always truly yours, James Paget." It is not in the handwriting of Sir James Paget. The firm who sent it to you assure me that it has been in their possession for some 30 years and that they have always regarded it as genuine. It may, of course, be a copy of part of a private letter written long ago by Sir James Paget, but there is not the faintest reason for thinking that it was written to the firm who have lately used it as an advertisement.

I am, Sirs, jours faithfully,

Jarley-street, W., Feb. 1st, 1905.

STEPHEN PAGET.

\section{THE TREATMENT OF PULMONARY TUBERCULOSIS.}

\section{To the Editors of THE LANCET.}

SIRS,-I was glad to see Dr. A. C. Falkiner in THE LANC'ET of Jan. 14th draw attention to the harm done by "stuffing " in sanatorium treatment. A great many patients, and unfortunately some doctors, are dissatisfied unless they see a weekly gain in weight. But everyone who has any experience of sanatorium treatment must remember cases where increase of weight and progress of disease have occurred at the same time. But even in favourable cases a rapid increase of weight throws a great strain on the heart and produces breathlessness and this in spite of uphill walking. Quite recently I saw a young man return from a short stay at a sanatorium with his lung distinctly improved but a pulse-rate never below 125 and going up to 140 and over on exertion, which undoubtedly was due to a large deposit of fat, and yet he was taking walking exercise up to five and seven miles per day. Another evil effect of "stuffing" is the respiratory distress produced by distension of the stomach. In a wellknown sanatorium I have seen patients rise from table and on walking a few yards commence gasping for breath. This is mainly produced by a large quantity of carbohydrate diet, which I maintain is the cause of much discomfort to phthisical patients. Of course the large amount of carbohydrate diet increases weight rapidly and so produces a favourable impression on the patient's friends of the result of the treatment. As to the effect of foggy, rainy winters on some cases, I think they do harm. I have watched cases even in Germany go downhill whenever the misty days began but improve on moving to a warmer and drier atmosphere. $A_{s}$ in every department of medicine it is wrong to dogmatise, but I am quite sure that many cases, especially in females have gone back through persevering in the "Spartan" methods during damp winters.

I am, Sirs, yours faithfully, $\mathrm{X}$

\section{NOTES FROM INDIA.}

\section{(From oUr SPECTAY CORRESPONDENT.)}

The Sanitary Condition of Simla.

THE occurrence of several cases of enteric fever in Simla in 1903 and 1904 amongst the Furopean and Eurasian population has called attention to the sanitary condition of this station. I understand that the Lieutenant-Governor of the Punjab has appointed a committee, consisting of the sanitary commissioner, the judge advocate general, the sanitary engineer, and the civil surgeon, to make full inquiries into the various complaints which have of late been made. Amongst other grievances may be mentioned the trenching of night soil and the foul smells along the Mall and other roads, the collections of putrefying matter permitted to remain, and the shortage of water during the summer months. The drinking water is in quality undoubtedly good. Simla is growing and the station is overcrowded and complaint is made that the houses are too close together one above the other on the hillsides. The sewage works are not yet completed and the arrangements for carrying off the sewage water are insufficient. The septic tank at the bottom of the valley is admittedly a success but the incinerator used for burning refuse works slowly and is of a crude construction. The dhobies wash the clothes in hill streams but also doubtless in foul pools. The cows and buffaloes are kept in crowded and dirty byres in the villages. It is suggested that the annual occurrence of fevers amongst the natives every spring may be due to typhoid fever but the registration of the causes of deaths is so defective that the supposition is mere guesswork. The milk-supply is open to grave suspicion of constant contamination.

\section{The Inereasing Plague Nortality.}

The plague mortality throughout India is rapidly mounting up. For the week ending Dec. 31st, 1904, there were 22,645 deaths, as compared with 19,465 for the previous seven days. The increase is almost entirely in the Punjab and the United Provinces. The detailed figures are : in the United Provinces, 9574, against 6822 last week; the Punjab, 4643, against 3940; Bombay districts, 3774, against 4154; Bengal, 2496 , against 2005; Hyderabad State, 516, against 809; Madras districts, 367, against 353 ; Rajputana, 314, against 345 ; Mysore State, 282, against 319; and Central India, 121, against 132. I have frequently drawn attention to the absence of mention of Poona city in these weekly figures, notwithstanding that plague has been raging very severely for two or three months past. The deaths in this city have been included in the figures for the Bombay districts but it appears that the recent outbreak caused 71 deaths in September, 654 in October, and 1337 in November. Since the census of 1901 when Poona was credited with 153,320 inhabitants, there have been no less than 15,587 deaths from plague alone. The rate of mortality during November was 104 per 1000 per annum from plague. This city has lost nearly 40,000 of its inhabitants from plague since the first visitation of the disease in 1896.

\section{Social Reforms amongst the Indian People.}

The recent Indian Social Conference in Bombay indicates a great change in the opinions of the leaders of the various native communities upon questions concerning social reform. I find a resolution was passed that the custom of child marriage is most injurious to the physical, economic, and social well-being of the people. In the Baroda State marriage of girls under 12 years of age has been discouraged by recent legislation. A motion was also carried expressing cordial sympathy with the temperance movement and adopting the resolution passed at the last All India Temperance Conference. A further motion considered enforced widowhood as an infringement of the rights of women and recommended that all obstacles in the way of the marriage of widows should be removed. It is not generally known what a large proportion of girls under ten years of age are married. The census gives a rate of 115 per 1000 females and for child widows 6 per 1000 females. This 